\title{
Current Situation of Titanium Research, Development and Applications in China
}

\author{
Hui Chang ${ }^{1 *}$ Lian Zhou ${ }^{1,2}$ \\ ${ }^{1}$ Institute of Advanced Materials/College of Materials Science and Engineering, Nanjing \\ Tech University, Nanjing, Jiangsu 210009, China \\ ${ }^{2}$ Northwest Institute for Nonferrous Metal Research, Xi'an, Shaanxi 710016, China \\ *ch2006@njtech.edu.cn
}

\section{$\underline{\text { Abstract }}$}

This planery paper reviewed the progress of titanium research, development, applications and industry in China during the past four years since the Ti-2015 conference in San Diego. Including additive manufacturing, material genome engineering technologies, low cost titanium and short manufacture processing, powder metallurgies and near net shape fabrication technologies, applications in marine, gas and oil exploitations, as well as consuming products. And the industry situation in China has also been reviewed.

\section{$\underline{\text { Introduction }}$}

In the past four years after Ti-2015 conference in San Diego, Chinese titanium research activites keep a very active situation, especially in additive manufacture technology, new alloys development and process optimization using material genome engineering technology, low cost titanium technologies, powder metallurgies and near net forming technologies and so on.

Additive manufacturing technologies have been developed very fast during the past four years, not only for the very large products(the largest one can be more than $6000 \mathrm{~mm}$ ) manufactured by powder feeding, but also for the complex and precise structures products manufactured by powder bed. Some of the productions have been used in the C919 airplane and other key equipments. Meanwhile, some new additive manufacturing technologies have been developed in China, such as arc additive manufacture, additive/decrease manufacturing etc.. Using material genome engineering technology to design new alloys and processing optimization have been paid much more attention during research works on 
titanium, and efforts have also been made on establishing a digital model of the relationship among the chemical composition, processing, microstructure, mechanical properties and service performances, for the sake of forward prediction and reverse design. Since the lower cost technologies of titanium always takes a very important position in titanium research, besides the traditional way of using cheaper elements addition instead of expensive ones, the short manufacture processing has also been considered. The powder metallurgy and near net shape fabrication technology has also made very fast progress in the last four years, for example, the very large parts with a height of more than $2400 \mathrm{~mm}$ and diameter of more than $1000 \mathrm{~mm}$ can be produced easily and the mechanical properties could achieve the same as forged ones. The PST TiAl alloy with a very good high temperature strength and room temperature ductility has also been developed in China. Other research activities mainly focused on some new alloys with higher strength, performance properties in seawater, consumer applications and so on.

The titanium industry of China is remained relatively stable during last four years, and by the end of 2018, the capacity of sponge titanium is 107 thousand tons, and the output of sponge is about 75 thousand tons. The capacity of titanium ingot is about 158 thousand tons and with an output of 75 thousand tons. The output and consumption of mill products is about 63 thousand tons and 57 thounsand tons, respectively. For the next four years, the capacity of sponge and ingot will keep stable or increase slightly due to the new factory setup, and the output and consuming will be increased about $10-20 \%$ because of the expanding applications in marine and other consuming goods, especially in kitchen accessories and daily life products.

\section{Situation of research activities}

\section{Extraction}

Try to develop some new extraction methods to get high quality and lower cost titanium metals was still paid much more attention by Chinese titanium metallurgical scientists in the past four years. As one of the innovation extraction technology developed by China, USTB technology is considered as low-cost and environmentally friendly methods for titanium extraction, and shows a bright future than any other technologies in China, and a pilot plant was established in 2018. Recently, the research activities are mainly foucsed on the more efficient soluble anode optimization, an arc furnace was used to prepare a $\mathrm{Ti}_{2} \mathrm{CO}$ solid solution that was casted to form a consumable anode for the electrochemical preparation of metallic titanium in a $\mathrm{NaCl}-\mathrm{KCl}$ molten salt without low-valance titanium ions, and the dissolution potential of the as-prepared $\mathrm{Ti}_{2} \mathrm{CO}$ solid solution is more negative than that of conventional powder sintering. The research results indicated that the cast $\mathrm{Ti}_{2} \mathrm{CO}$ solution was a promising consumable anode for the USTB process for stable and effective 
preparation of metallic titanium, the current efficiency can be reached more than $85 \%$, and the purity of products is $99.99 \%$, with the $\mathrm{O}$ content is about 200ppm. Figure 1 shows the XRD diffraction results of casting Ti2CO solution, and Figure 2 shows the SEM and EDS mapping images of Ti2CO synthesized by arc melting ${ }^{[1,2]}$.

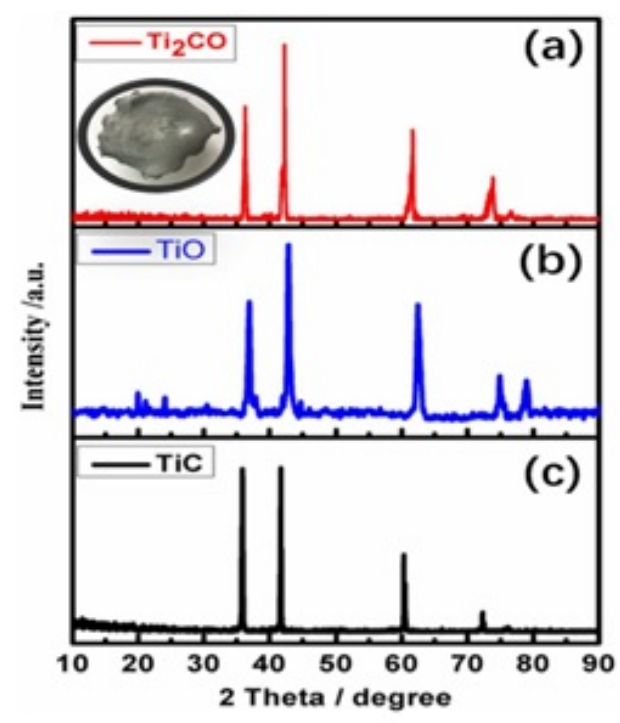

Figure l. The XRD patterns of (a) $\mathrm{Ti}_{2} \mathrm{CO}$ solid solution synthesized by arcfurnace, (b) $\mathrm{TiO}$ and (c) $\mathrm{TiC}$. Inset is the photograph of $\mathrm{Ti}_{2} \mathrm{CO}$
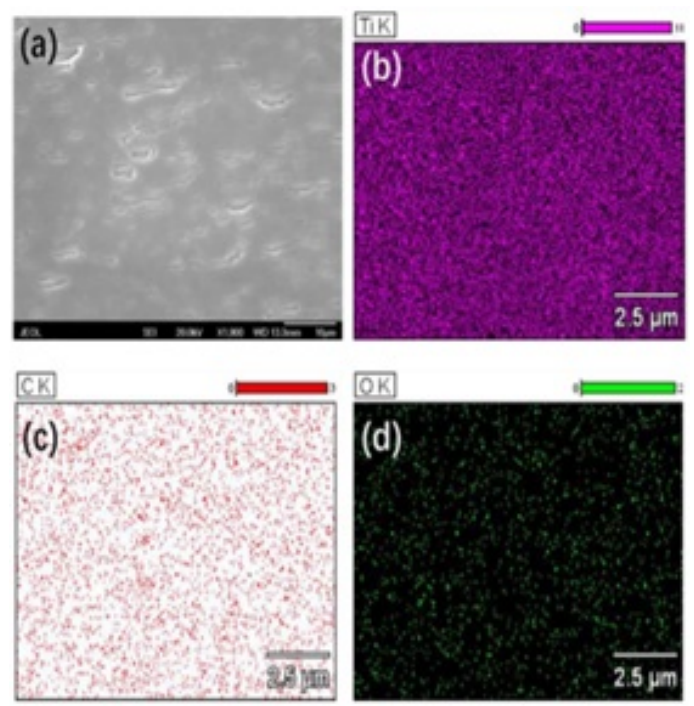

Figure 2. The SEM and EDS mapping images of $\mathrm{Ti}_{2} \mathrm{CO}$ synthesized by arcfurnace. (a) $\mathrm{SEM}$ image,(b-d) mapping images for the $\mathrm{Ti}, \mathrm{C}$, and O elements, respectively

Another new methods to produce low cost titanium metal and titanium alloys have been developed by thermal reduction of $\mathrm{TiO}_{2}$ in China in Northeast Unversity, recently[3,4,5]. The basic principle of multi-stage reduction can be described as: primary reduction: $\mathrm{TiO} 2+\mathrm{Mg} / \mathrm{Al} \rightarrow \mathrm{TixO}+\mathrm{MgO} / \mathrm{Al} 2 \mathrm{O} 3 \quad(x<1 \quad)$, deep deoxidation reduction: $\mathrm{TixO}+\mathrm{Ca}(\mathrm{g}) \rightarrow \mathrm{Ti}+\mathrm{CaO}$. The key technology for preparation of titanium powder/titanium alloy powder by magnesium-thermal SHS (primary reduction)calcium-thermal deep reduction (multi-stage reduction) was invented. The size of reduced titanium powder is about $200 \mathrm{~nm}$ with the oxygen content of $1500 \mathrm{ppm}$, and also the Ti64 powder can be reduced by the same way. TiAl, TiAINb alloy ingot also can be produced, with the oxygen content about 1500ppm. Figure 3 shows the morphology of reduced Ti powder and Ti64 powder as well as TiAl ingot. 

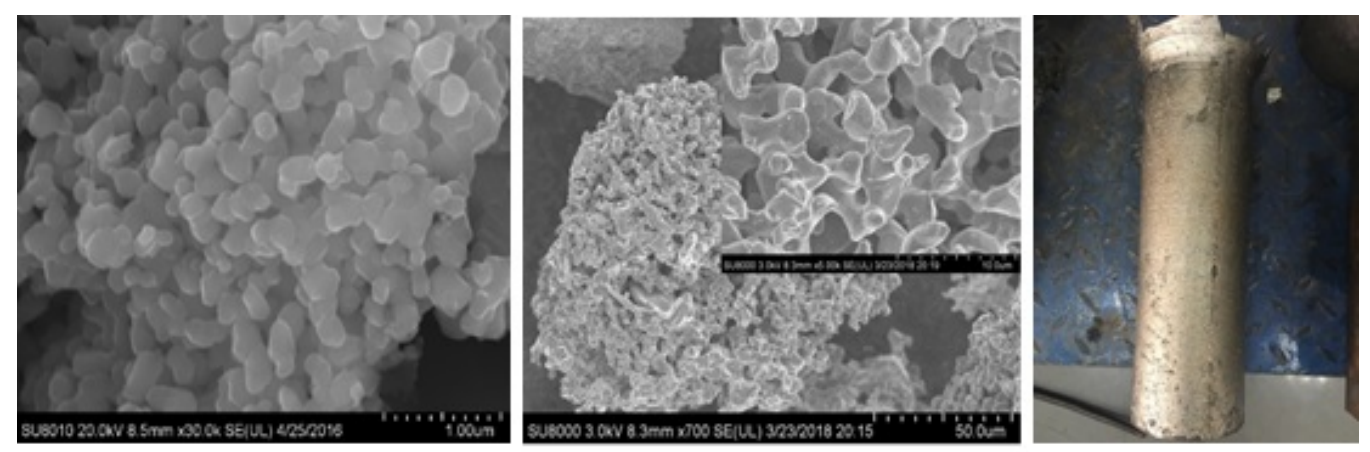

Figure 3 SEM morphology of reduced Ti powder(a),Ti64 powder(b), and TiAl ingot(c)(with a weight of $15 \mathrm{Kg}$ ) by using new method of thermal reduction of $\mathrm{T}_{2} \mathrm{O}$.

\section{Additive manufacture forming technology}

Additive manufacturing technology is one of the very attractive tenologies in China in the last four year, and there are more than 20 institutions that have joined the developing activities. The largest aircraft engine part have been successfully manufactured by using powder feeding technology by Prof. Wang and his team in recently ${ }^{[6]}$, and the projetction area can be reached $16 \mathrm{~m}^{2}$. Meanwhile, the processing of additive manufacture have been well controlled to get satisfaction microstructure and corresponding mechanical properties by controlling the solidification behaviors and grain morphology. The typical microstructure which is named "new special bi-modal microstructure" is discovered and threshold of fatigue crack growth has improved more than $60 \%$ compared with the conventional microstructure $^{[7]}$. The detailed information of the special bi-modal microstructure is shown in Figure $4^{[8]}$. 

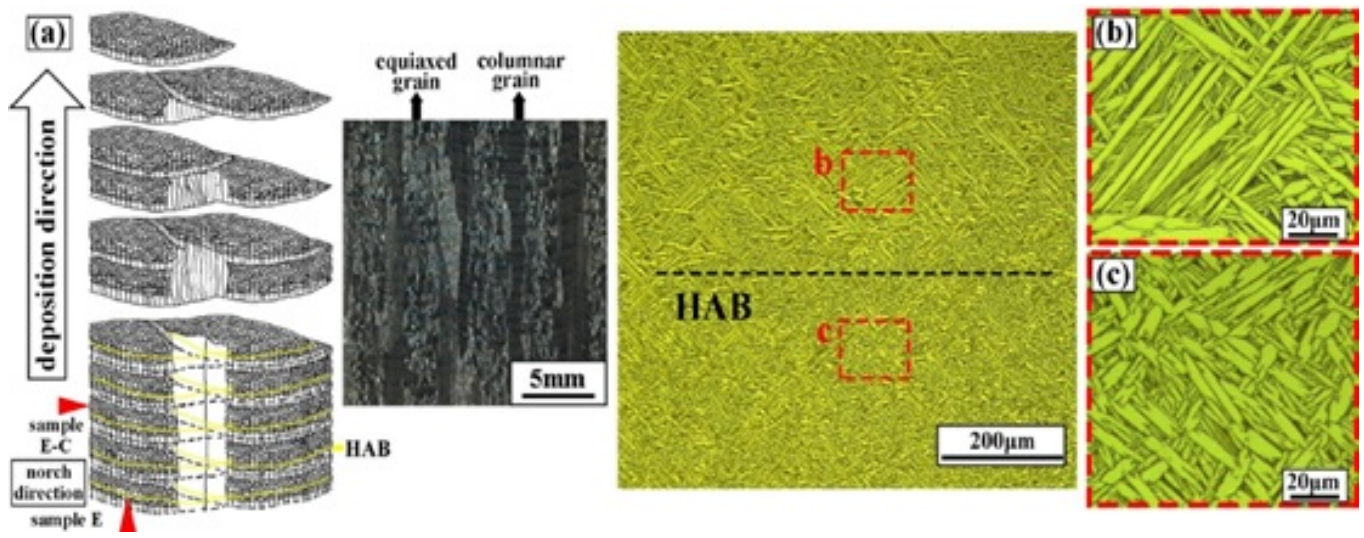

Figure 4. Microstructures of the LAM TC11 showing the HAB (a) and the difference in the microstructures between the HAB (c) and the remainder of the alloy (b).

In this field, some other research works have also been done by Chinese researchers, such as trying to manufacture titanium interconnected porous structure bone issues by using additive manufacturing technology with the computer-aided design, and its repair $[9,10]$. Scaffolds of new Ti35Zr28Nb beta titanium alloy have been prepeared by SLM technology with the porosity values of $85 \%$ and $50 \%$, respectively, and the proprtties and biocompatibility have been studied ${ }^{[11]}$. Another new alloy Ti2448 has also been used to form a porous bio-structure by EBM and with high strength-to-modulus ratio ${ }^{[12]}$. Arc additive manufacturing technology is one of the most efficient method to built some titanium structure than other ways, Chinese researchers have also paid a lot of attention to this technology $[13,14,15]$.

\section{TiAl alloy and MMCs}

The highlight of TiAl alloy development in China is that the Ti-45Al-8Nb single crystals have been fabricated scussefully with controlled lamellar orientations by directional solidification ${ }^{[16]}$. Samples with zero degree lamellar orientation exhibit an average room temperature tensile ductility of $6.9 \%$ and a yield strength of $708 \mathrm{MPa}$, with a failure strength of $978 \mathrm{MPa}$ due to the formation of extensive nanotwins during plastic deformation. At $900^{\circ} \mathrm{C}$ yield strength remains high at $637 \mathrm{MPa}$, with $8.1 \%$ ductility and superior creep resistance. 

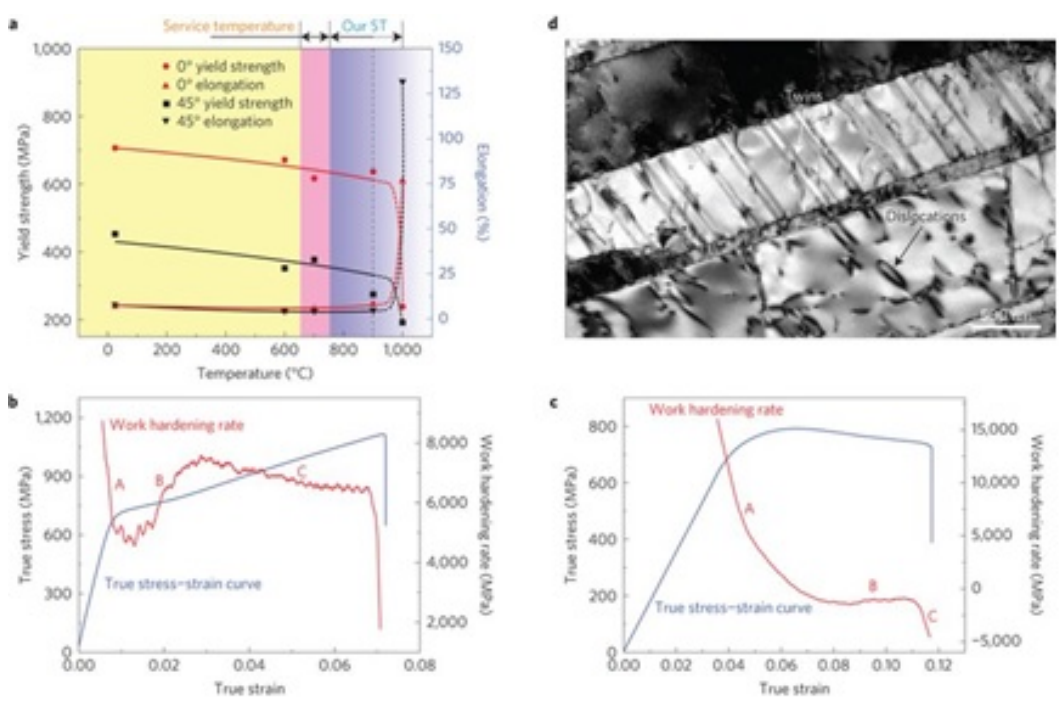

Figure 5 a) Mechanical properties as a function of temperature.

The well-aligned PST single crystal maintains a high yield strength of $637 \mathrm{MPa}$ at $900{ }^{\circ} \mathrm{C}$; a temperature much higher than the $650-750^{\circ} \mathrm{C}$ reported for polycrystalline alloys 4 (see the pink-colour region in the figure). b),c), The true stress-strain curve and the work hardening rate obtained at ambient temperature (b) and $900^{\circ} \mathrm{C}$ (c). d)TEM microstructure of wellaligned PST single crystals after tension tested at $900^{\circ} \mathrm{C}$. Twins and dislocations appear simultaneously after the elevated-temperature deformation ${ }^{[16]}$.

For high Nb-TiAl alloy, the Chinese developed new TiAl alloy, which still keeps very active, and the research works manily foused on the fatigue behaviors, microstructure reforcment and phase transformation kinetics etc. in the past four years ${ }^{[17,18,19,20]}$.

Titanium based composite materials is also a very attractive derection in titanium development in China. The resear works on particle( $\mathrm{TiC}, \mathrm{TiB}, \mathrm{La}_{2} \mathrm{O}_{3}$ and so on), fiber(carbon fiber,TiB fiber) and carbon nanotube reinforcement composite are still continuous, and have made some progress ${ }^{[21,22]}$. Graphene reinforced ${ }^{[23]}$ and nanodiamond reinforced ${ }^{[24]}$ titanium alloy are the newly attractive derection in titanium based composite research. Graphene reinforced Ti64 alloy was fabricated successfully by powder metallurgy process ${ }^{[23]}$, and it indicated that graphene could be introduced into Ti64 matrix homogeneously and the in-situ formed TiC particle could strengthen the interface bond between titanium and graphene during isothermal forging at $970^{\circ} \mathrm{C}$, and the tensile strength $(1058 \mathrm{MPa})$ and yield strength $(1021 \mathrm{MPa})$ were improved remarkably without loss 
of ductility $(9.3 \%)$ when $0.5 \mathrm{wt} \%$ graphene added. Figure 6 shows the optical and SEM images of graphene $(0.5 \mathrm{wt} \%)$ reinforced Ti64 alloy after isothermal forging at $970^{\circ} \mathrm{C}$.
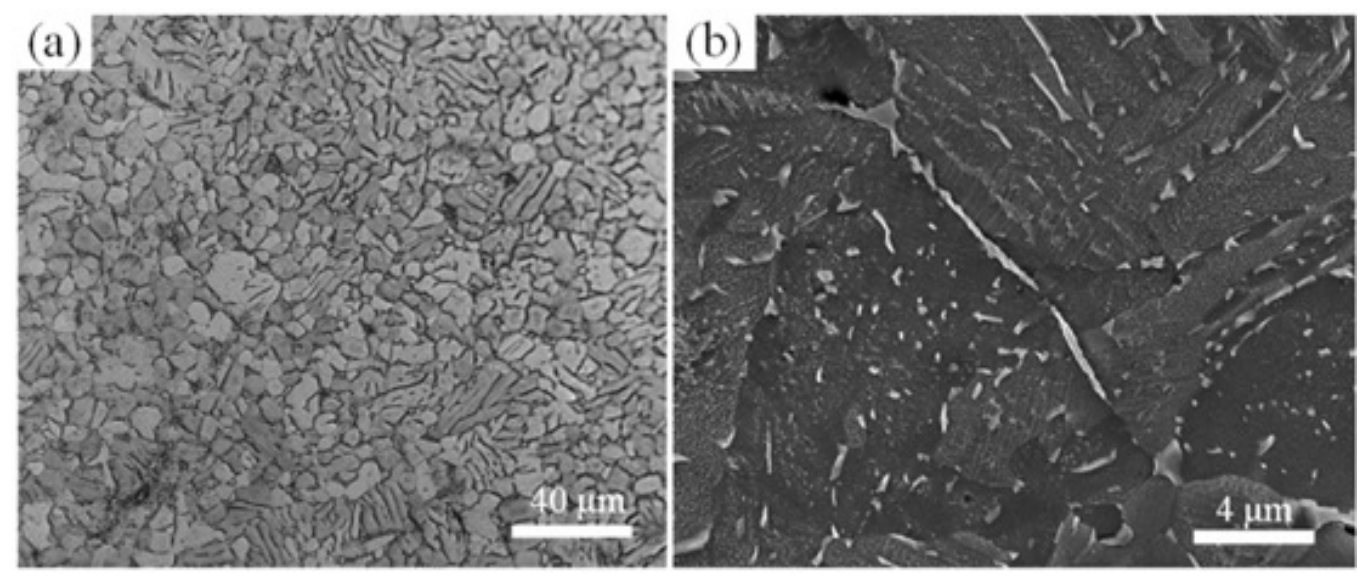

Figure 6 Optical microscopy (a) and SEM image (b) of the Ti-Graphene composite reinforced with 0.5 wt $\%$ Graphene after isothermal forging at $970^{\circ} \mathrm{C}$.

\section{Low cost technology}

Lower cost of titanim and titanium alloys as well as titanium low cost manufacture technologies are a very attractive research derections in China, and also a very important technologies for titanium large-scale applications. For lower cost titanium alloy design, the basic idea is using cheaper elements to replace the expensive ones, such as using Fe element to replace $\mathrm{V}, \mathrm{Mo}, \mathrm{Ta}, \mathrm{Nb}$, etc.. Recently, a novel $\alpha+\beta$ type titanium alloy Ti-3Al-8.5Cr-2Fe was developed by Shanghai Unversity by the Calphad method ${ }^{[25]}$. The mechanical properties testing results shows a very good comprehensive performance, and the average ultimate tensile strength $(\sigma \mathrm{b}), 0.2 \%$ proof strength $(\sigma 0.2)$ and elongation $(\mathrm{EI})$ of this alloy in thermo-mechanical state can reach $985 \mathrm{MPa}, 904.5 \mathrm{MPa}$ and $19.6 \%$, respectively, and it is a potential alloy for alternative of Ti64. Another idea to lower the cost of titanium alloy is trying to decrease the following stress during the deformation processing by chemical composition design or optimization. Based on this idea, Fe microalloying Ti64 alloy(named TC4-F) has been scussefully developed recently ${ }^{[26]}$, the hot deformation stress decreased more than $30 \%$ compared with the conventional Ti64 alloy during deformation in $800^{\circ} \mathrm{C}$ and $900^{\circ} \mathrm{C}$, and the tensile strength nearly keep in the same level, meanwhile, the fracture toughness can be reched to more than $110 \mathrm{MPa} \cdot \mathrm{m}^{1 / 2}$, the properties of TC4-F alloys after nomal annealed treatment are listed in Tab.1. So, Fe microalloyed Ti64 alloy shows a very comprehensive properties in strength and dutility as well as fracture toughness, that gives a potential way to reduce the cost of manufacture processing of Ti64 alloy. For the 
mechanism of reducing following stress and improving fracture toughness by addition trace amounts of $\mathrm{Fe}$ element, some research works are under going, and the preliminary results shows that the alpha and beta phase size, volume fraction as well as chemical composition have been changed in Ti64 alloy and TC4-F alloy, and a coupling effect of Fe and V element have been observed due to higher disffusion rate of $\mathrm{Fe}$.

Table 1. Properties of Fe microalloyed Ti64 alloy after nomal annealed treatment ${ }^{[26]}$

\begin{tabular}{|c|c|c|c|c|c|c|c|}
\hline Heat treatment & \multicolumn{2}{|c|}{ Samples } & $\mathrm{R}_{\mathrm{m}} / \mathrm{MPa}$ & $\mathrm{R}_{\mathrm{p} 0.2} / \mathrm{MPa}$ & $\mathrm{A} / \%$ & $\mathrm{Z} / \%$ & $\mathrm{~K}_{\mathrm{Q}} / \mathrm{MPa} \mathrm{m}^{1 / 2}(\mathrm{~T}-\mathrm{L})$ \\
\hline \multirow{6}{*}{ Anealed } & & No.1 & 984 & 941 & 16.0 & 46.0 & \multirow{6}{*}{111.20} \\
\hline & T-direction & No.2 & 981 & 920 & 13.5 & 40.0 & \\
\hline & & Average & 982.5 & 930.5 & 14.8 & 43.0 & \\
\hline & \multirow{3}{*}{ L-direction } & No.1 & 933 & 878 & 15.5 & 43.0 & \\
\hline & & No.2 & 933 & 862 & 16.5 & 45.0 & \\
\hline & & Average & 933.0 & 870.0 & 16.0 & 44.0 & \\
\hline
\end{tabular}

For the short-processing technology research works have also been done in some Chinese company and research institutions. One time EB remelting and followed by derectly hot rolling technology is one of the most attractive one and more than 500 tons of titanium plate have been produced in Chinese company of Yuntai ${ }^{[27]}$ and other company. And meanwhile, a continuous casting and derect hot rolling technology is under developing by SHANGI Institute for Advanced Materials(Nanjing) Co.,Ltd and Nanjing Tech University ${ }^{[26]}$.

\section{New alloys development}

In the past four years, some novel titanium alloys have been designed and developed in China. A novel ternary $\beta$-metastable titanium alloy, Ti-12Mo-5Zr (wt\%), was designed based on the "delectron" alloy design theory, and displays excellent combination of improved yielding stress $(>650 \mathrm{MPa}$ ), high ductility (uniform elongation $\approx 30 \%)$ and workhardening behavior ${ }^{[28]}$. Another novel high trength beta-titanium alloy with a chemical composition of Ti-5Al-4Zr-8Mo-7V(wt\%)was designed by using "d-electron theory", and shows an excellent combination mechanical properties with a tensile trength of $1460 \mathrm{MPa}$ and ductility of $10 \%{ }^{[29]}$. For the aerospace application, a new high strength and high tounghness titanium alloy named Ti-5321 alloy have been designed and fabricated, the 
tensile strength is over $1200 \mathrm{MPa}$, and elongation is over $8 \%$ and fracture toughness is over $65 \mathrm{MPa} \cdot \mathrm{m}^{1 / 2[30]}$. For the marine application, a excellent combination of strength and cold deformation titanium alloy Ti- $(1-2 \mathrm{wt} \%)$ Fe-B alloy has been designed, of which the tensile strength is about $600 \mathrm{MPa}$, yield strength is about $450 \mathrm{MPa}$, and elongation is more than $26 \%$, this alloy shows a very attractive application future in the marine engineering in China $^{[26]}$.

\section{Simulation and computation on microstructure and properties}

With the delelopment of computer technology and simulation modeling, the microstructure evolution and properties prediction have been a very efficience method in the research works on titanium for some more details. In China, a 3D microstructure-based micromechanical model was developed recently to evaluate the micromechanical response of TC6 titanium alloy subjected to uniaxial tensile loading ${ }^{[31,32]}$. By using this model, the stress-concentration translation among the constituent phases was observed and applied to the prediction of failure initiation in the TC6 alloy. The details of the 3D modeling construction is shown in Figure 7. A crystal plasticity-based finite element modelling (CPFEM) coupled with experiments have been used to study the micro-mechanisms of plastic anisotropy in lamellar TiAl alloys, for the in-depth understanding of micro-mechanisms responsible for the highly anisotropic deformation response of TiAl on the intra-lamella and inter-lamella scales ${ }^{[33]}$. For permance properties prediction, numerical simulations are conducted to investigate the fatigue behavior of anovel TA2-TA15 titanium alloy fabricated by the laser melting deposition (LMD) manufacturing process ${ }^{[34]}$. 


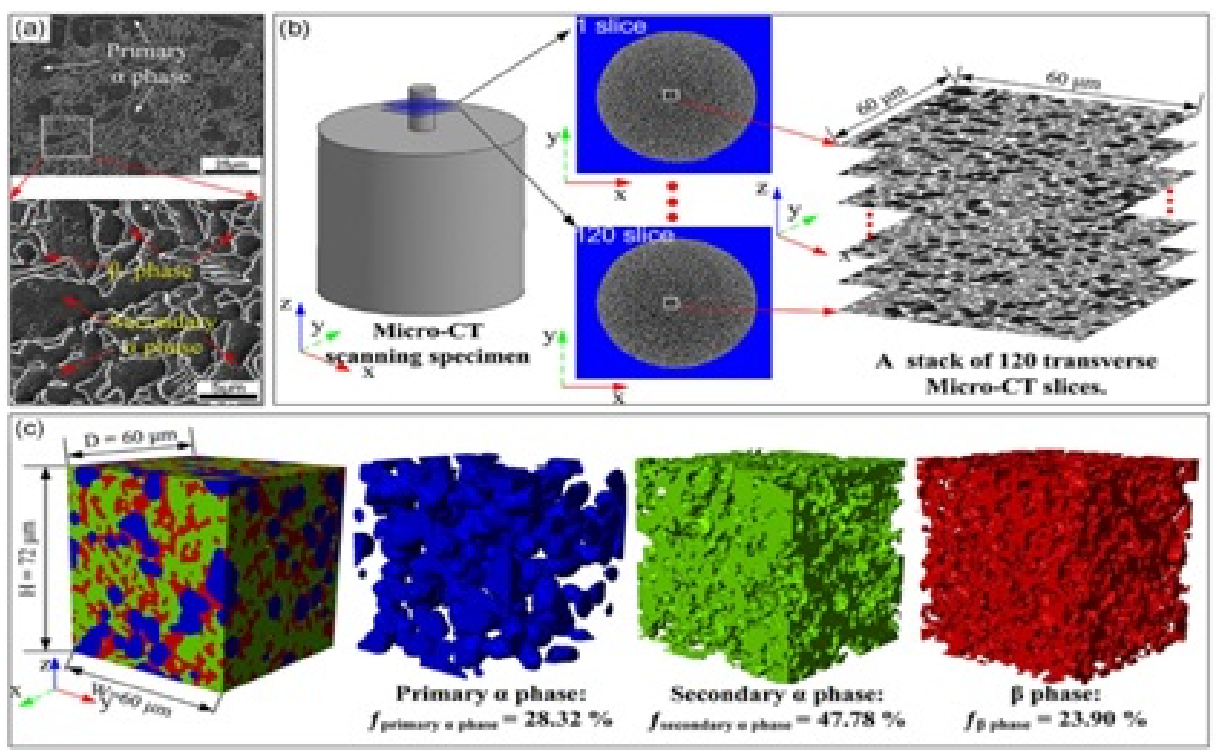

Figure 7 3D microstructural model reconstruction for the TC6 titanium alloy: (a) SEM image of annealed microstructure of the TC6 titanium alloy; (b) Diagram showing selection of the volume of interest in Micro-CT slices; (c) 3D microstructure model of the alloy.

\section{Situation of application}

\section{Marine applications}

Titanium alloy is the most ideal materials that can be used in marine applications due to its very excellent sea water corrorion resistance and high specific strength. The highlight of titanium application in marine applications is the spherical shell made from Ti64 ELI alloy for $4500 \mathrm{~m}$ deep submersible device manufactured by Baoti Group ${ }^{[35]}$. The shell was made by welding of two titanium hemispheric,and heat-treatment dwelled in vaccum by whole shell. The shell inner diameter is $2.1 \mathrm{~m}$, the wall thickness is $60 \mathrm{~mm}$ and the weight is 4 tons. Figure 8 shows the finished spherical shell of Ti64 ELI alloy. Titanium tube for mairne resources development is very active in China in recent years, Zhongshi High Tech Company have developed a kind of titanium alloy tubes for marine applications ${ }^{[36]}$. Figure 9 shows some of the products for marine applications developed by Zhongshi High Tech Company. 


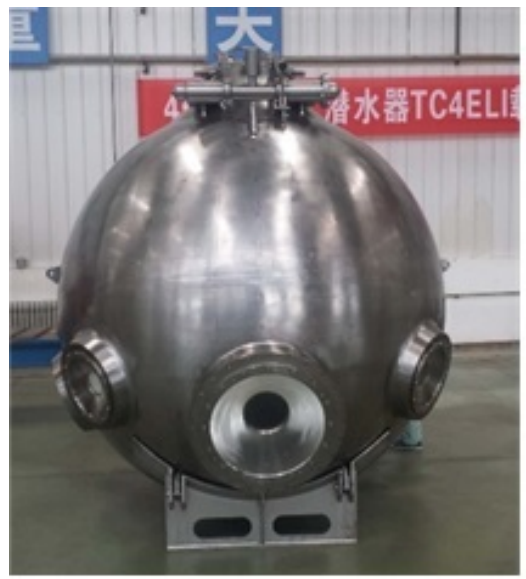

Figure 8 The w elding and heat -treatment finished spherical shell of T i64 E LI alloy (picture provided by BaoTi group)

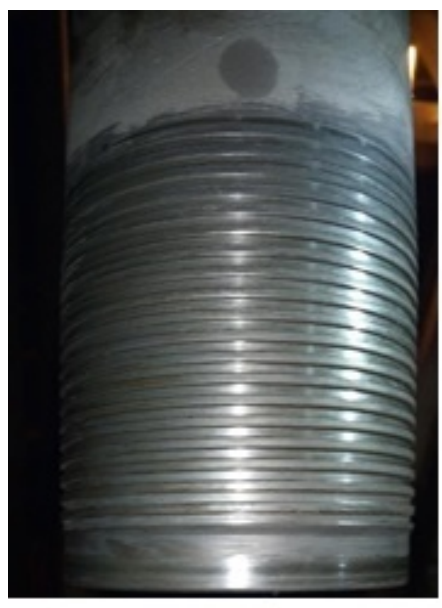

Figure 9 The tuber exterior surface and inner surface morphology after heavy loading tested (picture provided by Zhongshi High T ech)

\section{Kitchen accessories and daily life products}

Due to suffering from a very difficult period for small and medium titanium company in China in last few year, those company had to develop some emergency applications. The kitchen accessories and daily life products are the most highlighted development activities, and some complicated forming tachnologies and surface modification technologies have been developed and used for fabricating those goods. Now, there are about more than 30 company engaged in manufacturing kitchen accessories and daily life goods of titanium. Figure 10 shows some titanium kitchen accessories and daily life goods fabricated by TiLIVING company ${ }^{[37]}$. It is forcasted that, the market of titanium kitchen accessories and daily life will have a very bright future. 

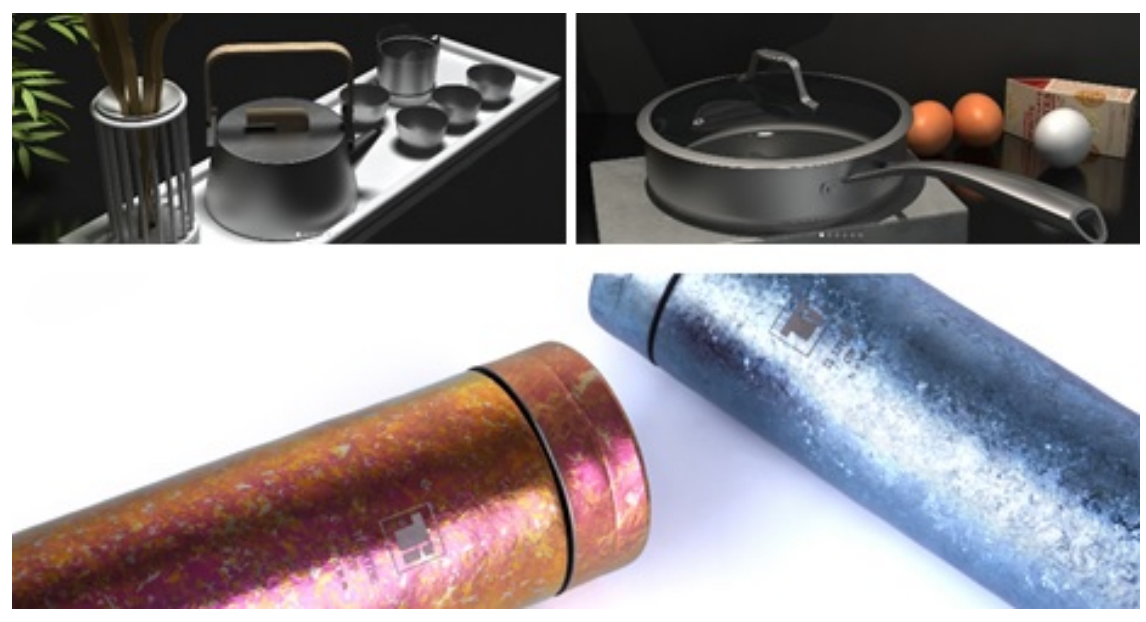

Figure 10 Titanium kitchen accessories and daily life goods fabricated by TiLIVING company

\section{Situation of titanium industry}

Since the Ti-2015 titanium conference in San Diego, titanium industry in China has kept a stable developing situation in the last 4 years. By the end of 2018, the actual capacity of titanium sponge is 107,000 metric tons, and shipment is 74,950 metric tons with 8 producers(the number of producers is decreased 30\% compared with the year of 2014). And the mill products shipment is about 63,396 metric tons with 30 producers; meanwhile the actual consumption of titanium mill production is 57,441 metric tons.

\section{Sponge}

Figure 11 shows the changes of capacities and outputs of titanium sponge in China during last 5 years. It can be seen that during the past 4 years, the capacity decreased(about $30 \%$ ) very much compared with year 2014, and output of titanium sponge has incresed a little bit. Whatever, the capacity of titanium sponge in China has taken a stage at 100,000 metric tons once more in 2018. At the end of 2018, there are totally 8 titanium sponge manufacturers in China, 4 manufacturers have been shutdown compared with year of 2014 . 


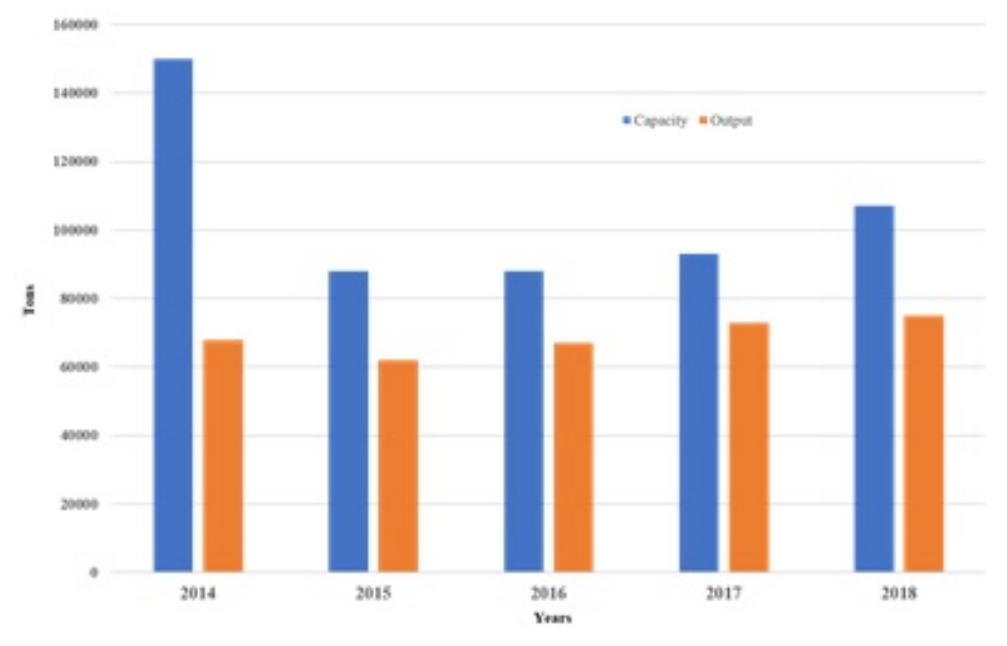

Figure 11 Changes of Capacity and output of sponge titanium in last 5 years in China

\section{Ingot}

In the past four years, titanium ingot capacity has kept increasing to more than 150,000 metric tons, which means that the ingot capacity has increased more than $28 \%$ than the year of 2014. Figure12 shows the changes of titanium ingot capacity and output in China during the last 5 years. It indicates that the titanium ingot capacity keeps increasing, and the average increase reate is about $8 \%$, the capacity of titanium ingot in China has arrived 158,700 metric tons, which is the top capacity in Chinese titanium industry. The actual output of titanium ingot in China also keeps increase during last 5 years, but the increase rate is now the same as capacity. Eventhough, the output of ingot still reached more than 75,000 metric tons, which is the highest output in the titanium industry history. 


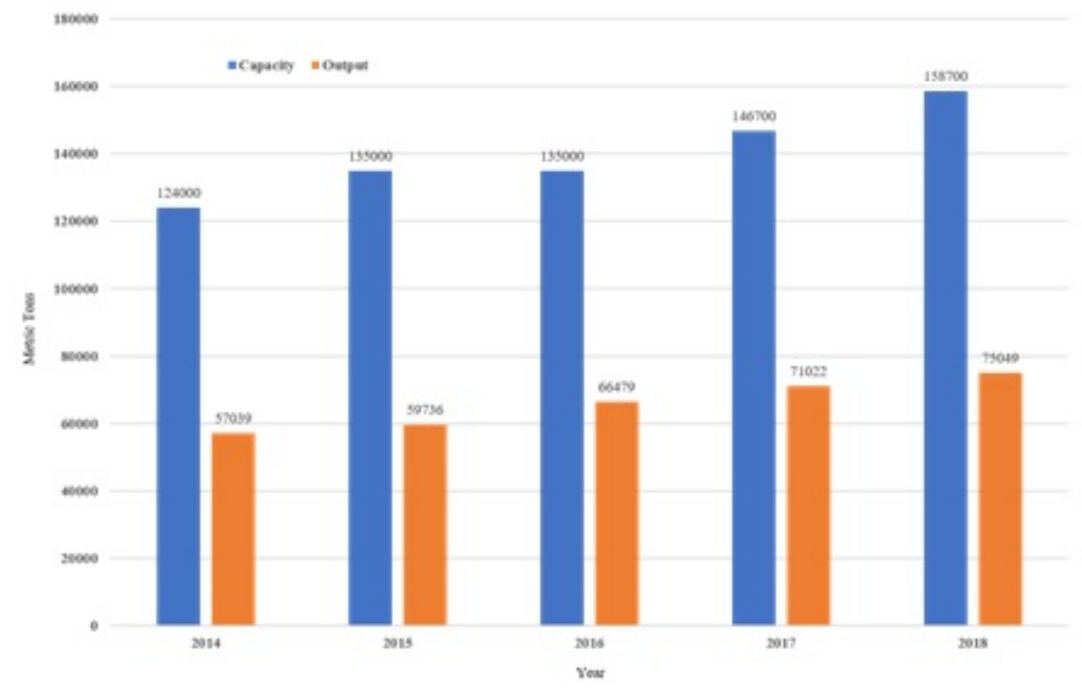

Figure 12 changes of titanium ingot capacity and output in China during the last 5 years

\section{Mill products and consumption}

Figure 13 shows the changes of output and consumption of titanium mill products in China in last 5 years, it can be seen that the output and consumption keeps increase during the last 4 years, and the output of mill products in 2018 is 63,396 metric tons, and creased about $27 \%$ compared with that of 2014. And the domestic consumption in 2018 is 47,044 metric tone, and increased about $25 \%$ compared with that of 2015 . The datas show that the output of mill products and consumption reached the highest amounts in Chinese titanium history. Figure 14 gives the comparion of the changes of consumption area in 2014 and 2018 in China, and it can be seen that the chemical area is still the biggest market in China, the consumption amount is about 26000 metirc tons, and increased about $25 \%$ compared with that in 2014. The consumption in aerospace, shipbuilding, medicine application, marine application as well as other application have been increased remarkable thanks to the great market demands.

For the next four years, the capacity of sponge and ingot will keep stable or increase slightly due to the new factory setup, and the output and consumption will be increased about 10$20 \%$ because of the expanding applications in marine and other consuming goods, especially in kitchen accessories and daily life products. 


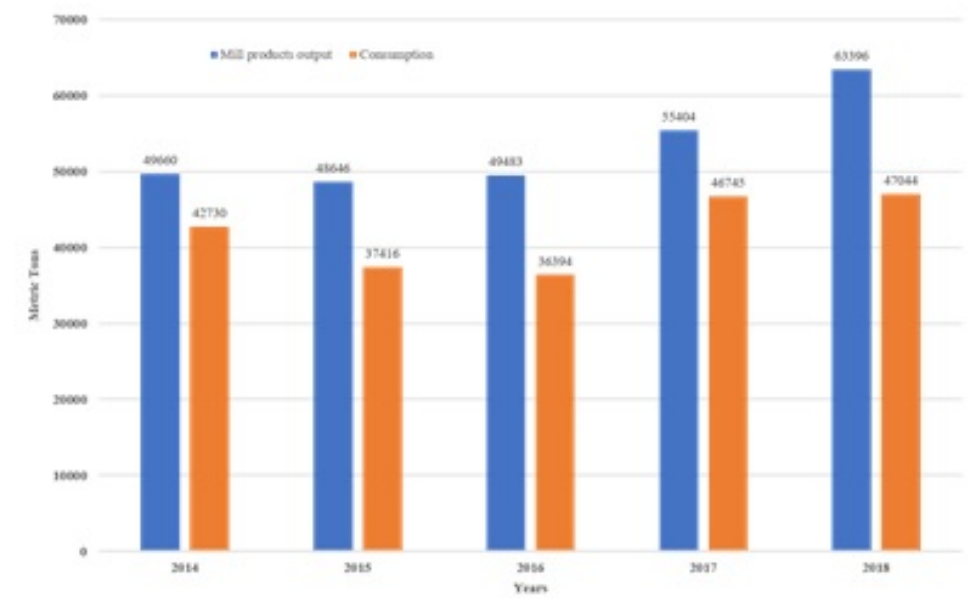

Figure 13 Changes of output consumption of titanium mill products of China in last 5 years.

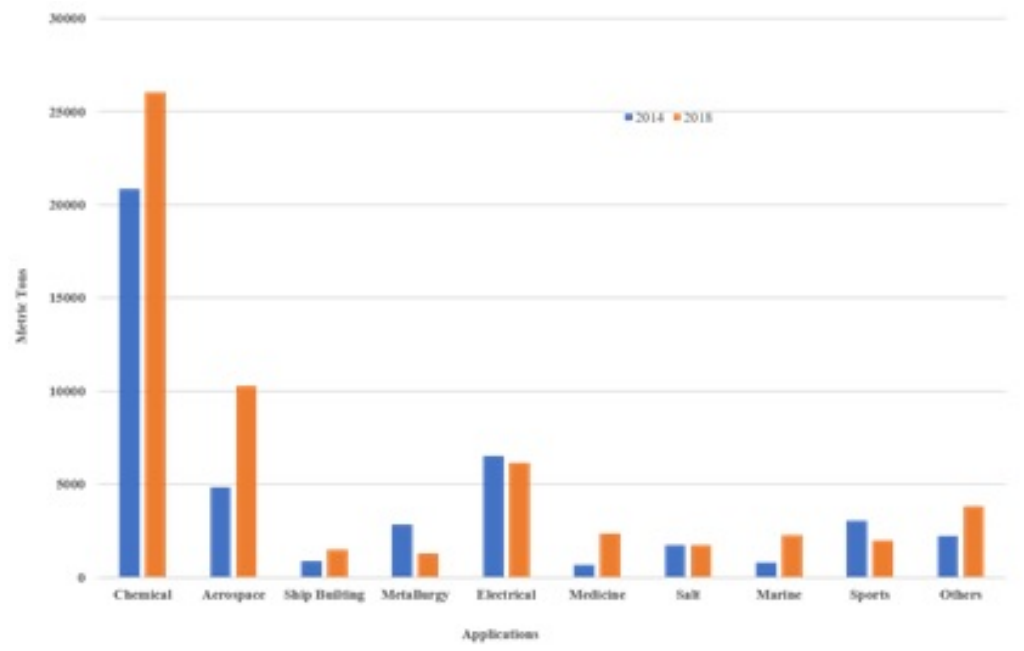

Figure 14 Changes of consumption aereas of Titanium in 2014 and 2018 in China.

\section{$\underline{\text { Summary }}$}

In the last 4 year, Chinese research, development, applications and industry keeps very active and stable. The extraction methods, additive manufacture technology, TiAl alloys and MMCs, low-cost titanium technologies, new alloys design and development as well as the applications have been made great progress, and give a strong support for the industry 
development. The titanium industry have been overcoming the very difficult time since the Ti-2015 conference, and will keep a suitable increasing rate in next few year thanks to the great demands from marine applications and daily life goods.

\section{$\underline{\text { Acknowledgment }}$}

The authors would like to extend thanks to Mr. Shuqiang Jiao, Mr. Zhihe Dou for providing important documents in extraction. Thanks for Mr. Hongkang Zhu for his contributions on this paper.

\section{Reference}

[1]. Donghua Tian et al. Journal of The Electrochemical Society, 166 (8) E226-E230 (2019)

[2]. Xiaohui Ning et al. Journal of The Electrochemical Society, 166 (2) E22-E28 (2019)

[3]. Shin-Gang Fan et al. Metallurgical and Materials Transanction B, 282-Volume 50B, Feb. 2019

[4]. Chu Cheng et al. JOM, Vol. 71, No. 2, 2019

[5]. Y. Song et al. Journal of Alloys and Compounds 789 (2019) 266-275

[6]. http://www.cnmn.com.cn/ShowNews1 .aspx?id=409037

[7]. T. Wang et al. Journal of Alloys and Compounds 632 (2015) 505-513

[8]. Y. Wang et al. Journal of Materials Science \& Technology 35 (2019) 403-408

[9]. X. Pei et al./Materials Letters 208 (2017) 133-137

[10]. L. Zhao et al. Composites Part B 162 (2019) 154-161

[11]. Y. Li et al./Acta Biomaterialia 87 (2019) 273-284

[12]. Y. Liu et al. Journal of Materials Science \& Technology 32 (2016) 505-508

[13]. Z. Li et al. Materials Science \& Engineering A 742 (2019) 287-294

[14]. J. Wang, et al. Additive Manufacturing 27 (2019) 236-245 
[15]. Y. Xie et al. Materials Science \& Engineering A 737 (2018) 310-317

[16]. Guang Chen et al.Nature materials, Vol.15 August 2016

[17]. L. Chen et al. Journal of Alloys and Compounds 741 (2018) 1175-1182

[18]. J. Ding et al. Acta Materialia 161 (2018) 1-11

[19]. J. Ding et al. Acta Materialia 145 (2018) 504-515

[20]. Y. Li et al. Journal of Alloys and Compounds 668 (2016) 22-26

[21]. Y. Jiao et al. Journal of Alloys and Compounds 767 (2018) 1196-1215

[22]. H.Duan et al. Materials and Design 99 (2016) 219 -224

[23]. Z. Cao et al. Journal of Alloys and Compounds 696 (2017) 498-502

[24]. F. Zhang et al. Materials \& Design 131 (2017) 144-155

[25]. J. Wang et al. Materials Science \& Engineering A 732 (2018) 63-69

[26]. Hui Chang et al. $17^{\text {th }}$ National conference on titanim of China, Nanjing, 14-17 April 2019

[27]. Yaming Shi. Workshop on low cost titanium technology, Beijing, 29-30 November 2018

[28]. J. Zhang et al. Materials Characterization 139 (2018) 421-427

[29]. W. Zhu et al. Materials and Design 168 (2019) 107640

[30]. Yongqing Zhao et al. Materials China,2016,(12):041-45

[31]. G. Li et al. Materials Science \& Engineering A 685 (2017) 327-331

[32]. G. Li et al. Materials Science \& Engineering A 675 (2016) 212-220

[33]. Liu Chen et al. International Journal of Plasticity, https://doi.org/10.1016/j.ijplas.2019.04.012

[34]. Z. Zhan International Journal of Fatigue 121 (2019) 20-29

[35]. http://baoji.hsw.cn/system/2017/0426/17978.shtml 
[36]. Xiaohu Wang The $4^{\text {th }}$ sumit forum on marine materials industry of China, Nantong,17-19 Apr. 2019

[37]. http://www.ti-living.com/project/cid/82307/

[38]. Hong Jia, et al. Annual Report of Chinese Titanium Industry (2014)

[39]. Hong Jia, et al. Annual Report of Chinese Titanium Industry (2015)

[40]. Hong Jia, et al. Annual Report of Chinese Titanium Industry (2016)

[41]. Hong Jia, et al. Annual Report of Chinese Titanium Industry (2017)

[42]. Hong Jia, et al. Annual Report of Chinese Titanium Industry (2018) 